\title{
Teaching Application of Computer Multimedia Cloud Sharing Technology in Hand - painted Performance Course in Colleges and Universities
}

\author{
Shuai Yang ${ }^{1,2, a}$, Yue Huang, b \\ ${ }^{1}$ Zhuhai College of Jilin University \\ Zhuhai 519041, China \\ ${ }^{2}$ Faculty of Urban Management and Studies, City University of Macau \\ Macau, China \\ aU17092105159@cityu.mo, ${ }^{\mathrm{a}}$ huangyue13597@ hotmail.com
}

\begin{abstract}
With the further use of modern technology such as computer, the collection of teaching materials, the emergence of teaching process and students' understanding ability have changed dramatically. People are paying more and more attention to lifelong learning, the demand for digital resources is also improving, especially the excellent teaching resources of colleges and universities by more people of all ages. China's remote network education provides a lot of resources for people with deep learning needs, but there are serious shortcomings in this way. Students can only obtain distance education resources for a fixed period of time. After the course is finished, they can no longer $\log$ in. The education system will continue to receive learning resources, which is not conducive to the student's lifelong learning. The college art teaching, students can make full use of multimedia technology in the cloud technology to achieve the purpose of expanding horizons, but also in the above direct painting design or appreciation, effectively improve its overall quality and creativity. Through the multimedia cloud sharing way to start art teaching, as the current college art reform key. The cloud sharing technology in the hand-painted performance course is particularly critical and will help to improve the efficiency of learning hand-drawing and improve the quality of teaching.
\end{abstract}

Keywords-Cloud sharing; Computer multimedia; Handpainted performance

\section{MULTIMEDIA CLOUD SHARING TECHNOLOGY IS}

\section{CONDUCIVE TO THE INTEGRATION AND USE OF INFORMATION}

Hand-painted performance course as a class of handpainted technical courses, each class cannot be separated from the detailed visualization of the image. The visual effect of hand-painted technique has its extensive and representative, and it will directly affect the students' main idea and teaching quality. For this reason, the teaching process of hand-painted techniques, teachers in addition to the traditional way to teach theoretical knowledge and concepts, supplemented by some demonstration techniques, but also requires the rational use of media in the preparation of the media and the network to find out the relevant teaching information, In particular, some video information, through the computer cloud to share their records, to prepare for students to learn and appreciate the classroom.
With the further development of cloud computing technology, it is possible to integrate the educational resources of a country and even the whole country into "educational resources cluster" in order to unify the management and promote the effective integration of the mathematics education resources so as to save the sharing cost and promote the good spread of information, to achieve the best digital educational resources sharing purposes [1]

In addition, you can get the "cloud" learning information at any time, store relevant learning resources, through open learning, strengthen the self-learning skills, effectively wrestling education information development. The handpainted teaching materials of the mourning and production, can be used is very rich means, the traditional hand-painted teaching only through sketches, print records of the way to collect hand-painted teaching and related creative material. At present, not only through the computer to carry out extensive access, but also in the course of practice, through the camera, camera and other means to effectively mourn and organize the relevant information, copy and scan into the computer, and then uploaded to the cloud sharing [2]. But also to the collection of video information to be soundtrack, through the picture and the text prompts to improve. In addition, you can also understand the needs of teaching content, made of special teaching courseware stored in the computer hard drive, so as to take with the take. In this way, it greatly enriched the teaching content, but also to enhance the quality of teaching purposes is bound to harvest a good teaching effect.

\section{MULTIMEDIA CLOUD SHARING TECHNOLOGY CAN CREATE A VIVID CLASSROOM ATMOSPHERE}

Hand-painted teaching to achieve illustrations, vivid image of the effect of the original teaching methods and methods have been insufficient to meet the needs of modern hand-painted, the traditional teaching method is more rigid, not rich enough. Although the traditional method has a relatively complete system, but compared to the use of modern information technology is less, the use of multimedia in hand-painted teaching can be more vivid, so that the content of textbooks knowledge "live" up, so that students are more interested. 
Psychology studies show that vivid images, bright colors and sweet sounds can better attract students' attention. So, from this point of view, teaching the use of intuitive teaching can have a better effect, so that the intuitive feeling of students instead of boring concepts, vocabulary. Therefore, multimedia for handpainted teaching can not only create a relaxed learning atmosphere for students, but also improve student interest and improve teaching efficiency. Hand-painted teaching in colleges and universities, including two parts of professional theory and professional skills, the use of multimedia technology in handpainted teaching, so the content will be richer, more flexible teaching methods. Especially the professional and technical teaching, the effect is more obvious, such as teachers to lead students to field students to copy, observation, can improve the students 'visual sensibility, so that students' understanding, appreciation and expression can be greatly improved. This kind of intuitive teaching method is more flexible, will not be limited by time and space, and the traditional method of students' sensory sources is limited to textbook knowledge, so cannot have full understanding and observation of things, for the same thing description, will be affected by the time and space, so students can only see the phenomenon, cannot understand its essence. And now teaching methods to break this limitation, teachers make full use of multimedia technology for hand-painted teaching, so that students feel things and process, through the vivid picture, sweet voice and image of the process, so that students experience the specific mood. Multimedia teaching to solve many of the past problems, through the visual reproduction of things to describe the phenomenon, phenomenon or process to solve the past with language description indescribable things and processes, so that students have a better visual experience, the teacher's teaching efficiency will significantly improve, so that students can have a more profound understanding, enhance student interest. Teachers in the teaching, teachers in order to enable students to have a broader perspective, a more comprehensive understanding of professional knowledge, allowing students to watch other relevant institutions of teaching films, so that students find the lack of comparison, learn their advantages, in the study to do In addition, students can also enjoy some of the outstanding works abroad, to expand the knowledge of students, the development of students creative thinking. For some boring professional class theory knowledge, student interest is not high, and even very tired, for example, art professional theory and Chinese and foreign art theory courses, these teachers will find that cannot find points of interest. In this case, teachers can make these theoretical content into a variety of courseware with multimedia player, so vivid picture of the screen instead of the boring content of knowledge, so that students in the new context so that students learn professional knowledge, so students Interest in the classroom efficiency is also higher. For example, teachers explain the "Western art history Impressionist painter". In order to attract students' interest, you can let the students first enjoy some Western art films, and then introduce students to some of the life experiences of painters such as Monet, Van Gogh, Camille Pissarro, so that students have a preliminary understanding, using the production of multimedia courseware to explain the impressionist expression techniques, style and view theory. From the whole classroom effect, through the pictures and music appreciation, a preliminary understanding of the impressionist, and then do a brief introduction to the impressionist painter, such as their life, ideas, style, ideas and creative techniques, so that students interested, and then through the vivid explanation of teachers, so that students have a deeper understanding of the Impressionist, fully understand the impressionist core ideas, style and characteristics [3].

\section{MULTIMEDIA CLOUD TECHNOLOGY CAN IMPROVE STUDENTS' AESTHETIC ABILITY TO ART WORKS}

For hand-painted teaching, the cloud multimedia display pictures for students to appreciate the art, shared in each school terminal, to give students a richer image content, and then with the sweet voice combined to form a relaxed and pleasant environment, to the students to Immersive feelings. Such as allowing students to enjoy Botticelli's "spring", by playing pictures, so that students can fully feel the vibrant spring scene. Can let the students have the feeling of immersive on the screen, the breeze blowing golden orange forest, they with the wind waves of waves to give people unlimited reverie; ground daffodils, hyacinths, tulips, etc., exquisitely decorated on the ground, Cheerfully bloom, gives a beautiful realm. Enjoy the "Mona Lisa" works of art, Mona Lisa elegant image presented in front of the students, her very typical smile for students to have wonderful imagination, and from her appearance to students to bring more fascinating imagination, So that students more profound taste of mood. Enjoy Xu Beihong's "group Ben", this work in the six horse combination presented on the screen above the composition of the arrangement, the ink shades of grasping the painter embodies a solid painting skills and highly talented imagination. Painters use a large angle perspective caused by the intensity, with the color of the distinction between primary and secondary, the use of thick ink, heavy color and high light at the white part of the contrast, the image of the horse to express the dynamic. Russian famous writer Chernyshevsky has this sentence: "From the definition of beauty, if we cannot feel it, then it is not beautiful." So the multimedia can bring students a real sense of existence, not only to enable students to feel, but also make their spirit and art to resonate, to have a more intense feelings, to stimulate students' aesthetic taste, so that students feel the beauty of the existence, to be able to inspire creative inspiration, improve the artistic quality of students [4].

\section{MULTIMEDIA CLOUD TECHNOLOGY CAN BREAK THE BOUNDARIES OF TIME AND SPACE AND MAKE UP FOR THE SHORTCOMINGS OF TEACHERS' TEACHING}

First of all, the multimedia teaching model of cloud technology broke the limit of space and time, as the Internet of things, cloud computing, big data, new media, such as artificial intelligence, virtual reality technology innovation, make the use of multimedia technology has brought great convenience to our lives, a new era of students through the Internet innovation for many times, they have a common characteristic, which have deliberately skills for using of the Internet technology. To use new media cloud computing way of teaching, students would get a large extent allows to break the specific time and space, no matter the specific time or location, regardless of the teacher, students are able to pass the new media for autonomous learning [5]. The teaching method of teachers and 
students can also become diversified, classroom teaching, distance learning, video conference to discuss can be implemented, such as the marriages of the original way of fixed point class regularly, make the class more flexible. It also an extremely advantage way to save time and space [5].

In addition, it is the arrival of the technology era, and the progressive of technological. For teaching, some knowledge is relatively abstract, and also, many new knowledge is coming into being with the passage of time, if teachers still teach on the stage alone by one person and without any teaching tools, even if used up over skills, due to the limitation of its own knowledge system, may be difficult to fully express all of the content, so that the students are difficult to full grasp and understanding. Therefore, the knowledge that students learn only in the class is very limited. Especially for the class of courses which name is hand-painted performance techniques, a lot of knowledge is gradually graphing, if it is still simple to rely on the teacher's explanation, that would be very difficult to express the hand painting performance method clearly. At the same time, hand-painted performance techniques involving a large number of hand-painted practice in the course, a student need to consult the related material, make sure the right practice subject and combined with good creative ideas, after that they can success in doing this job. If you use the computer multimedia cloud technology, you can achieve the result with half the effort. Due to the huge multimedia knowledge structure, the diversity of looking for knowledge, and the sound and texts, are capable to attract students' attention successfully, after makes the student to obtain other than teachers explain a lot of knowledge and content. For example, in hand-painted performance techniques course, students who need to learn and draw lessons can be found the excellent works through Internet channels, at the same time ,they can check through the Baidu searching, Google or even other professional environmental art design sites for large area to find pictures and literature, in order to obtain inspiration, thus, multimedia cloud technology education played a very important role, if students intuitive to explore to express the content and the inspiration through the use of multimedia and network, which will give them the immersive feeling, this kind of fresh and huge technical system support can make the teacher a good grasp of knowledge, and also can enrich students' learning content at the same time [6].

\section{CONCLUSION}

Art teaching makes full use of even more cloud sharing technology, and this technology and traditional teaching organic combination, creating a new scene, so that students have a more intense interest, is conducive to classroom efficiency. However, multimedia teaching as a supplementary teaching model, art teaching or to the traditional teaching-based, at the right time and content can use multimedia teaching, it cannot use multimedia. For example, hand-made, art sketching, practical operation, etc., cannot be replaced by computers, teachers must lead students to experience [7]. Therefore, some operational knowledge cannot be replaced by the computer, according to the specific teaching content to take the appropriate way [8].

For the use of multimedia cloud technology teaching course, if you can improve the enthusiasm of students, let students have more effectively communicate learning content, and also active all the students' atmosphere at the same time, you can directly take multimedia cloud computing technology into your teaching [9]. On the contrary, If some courses only treat the multimedia teaching as the tool of assistant teacher lectures, consider of this kind of institution, you can use the way of combining teaching and multimedia cloud technology teaching methods in your class, on the basis of different courses and take effective means of class. However, for the hand-painted performance techniques in the course, through repeated practice, I finally found that the multimedia cloud technology teaching has greatly increased the students' learning mood, making them become more and more confidence in learning this course, and greatly improve the teaching efficiency [10].

\section{REFERENCES}

[1] Editorial board, Digital Multimedia Technology and Application Examples, Electronic Industry Press. (2011).

[2] DuWenjie, Design Example of Digital Multimedia Courseware, Tsinghua University Press. (2016)

[3] LiSida, Digital multimedia and Introduction to Art,Tsinghua University Press.(2015)

[4] ZhouHongchun,, The change of teaching mode in colleges and universities under the new media communication environment, China electrochemical education.(2013)

[5] YanXingya, Introduction to Digital Media, Tsinghua University Press. (2012).

[6] Sunning, Sunchen.New media environment analysis based on teaching resource construction, China electrochemical education.(2017)

[7] WangZhengyou, Digital media design and production, Chongqing University Press. (2012).

[8] Zengyu, Discussion on computer network application course in new media environment, Education and teaching research. (2009)

[9] https://wenku.baidu.com/view/b2361c8ba0116c175f0e48f7.html.

[10] https://wenku.baidu.com/view/f153b1e4a58da0116c1749bf.html?mark_ pay_doc $=0 \&$ mark_rec_page $=1 \&$ mark_rec_position $=4 \&$ clear_uda_para $\mathrm{m}=1$. 